\title{
Vitamin D deficiency is associated with
}

\section{development of subclinical coronary artery disease in HIV-infected African American cocaine users} with low Framingham-defined cardiovascular risk

\author{
This article was published in the following Dove Press journal: \\ Vascular Health and Risk Management \\ 14 November 2013 \\ Number of times this article has been viewed
}

\author{
Hong Lai' \\ Elliot K Fishman' \\ Gary Gerstenblith ${ }^{2}$ \\ Richard Moore ${ }^{2}$ \\ Jeffrey A Brinker ${ }^{2}$ \\ Jeanne C Keruly² \\ Shaoguang Chen ${ }^{3}$ \\ Barbara Detrick ${ }^{3}$ \\ Shenghan Lai ${ }^{1-3}$ \\ 'Department of Radiology, \\ 2Department of Medicine, \\ ${ }^{3}$ Department of Pathology, Johns \\ Hopkins School of Medicine, \\ Baltimore, MD, USA
}

\begin{abstract}
Chronic cocaine use may lead to premature atherosclerosis, but the prevalence of and risk factors for coronary artery disease (CAD) in asymptomatic cocaine users have not been reported. The objective of this study was to examine whether vitamin D deficiency is associated with the development of CAD in human immunodeficiency virus (HIV)-infected African American cocaine users with low CAD risk.

Methods: In this prospective follow-up study, we investigated $169 \mathrm{HIV}$-infected African American cocaine users with low Framingham risk at baseline. The main outcome measures were incidence of subclinical CAD and development of subclinical CAD.

Results: Fifty of the 169 African Americans had evidence of subclinical disease on the initial cardiac computed tomography. A second cardiac computed tomography was performed on the 119 African Americans without disease on the first scan. The total sum of person-years of followup was 289.6. Subclinical CAD was detected in 11 of these, yielding an overall incidence of 3.80/100 person-years (95\% confidence interval 1.90-6.80). Among the factors investigated, only vitamin D deficiency was independently associated with development of subclinical CAD. The study did not find significant associations between CD4 count, HIV viral load, or antiretroviral treatment use and the incidence of subclinical CAD. This study appears to suggest that there is a threshold level of vitamin $\mathrm{D}(10 \mathrm{ng} / \mathrm{mL})$ above which the effect of vitamin D on subclinical CAD is diminished.
\end{abstract}

Conclusion: The incidence of subclinical CAD in HIV-infected African American cocaine users with low CAD risk is high, especially in those with vitamin D deficiency. Well designed randomized clinical trials are warranted to confirm the role of vitamin D deficiency in the development of CAD in HIV-infected African American cocaine users with low CAD risk.

Keywords: vitamin D deficiency, subclinical coronary artery disease, cocaine use, prospective follow-up study, African Americans

\section{Introduction}

With the use of noninvasive coronary imaging, we reported that chronic cocaine use is associated with coronary atherosclerotic plaque in young-to-middle-aged African Americans with no symptoms of coronary disease. ${ }^{1-4}$ We also reported in crosssectional investigations that both chronic cocaine use and vitamin D deficiency were independently associated with significant coronary stenosis. ${ }^{5,6}$ To explore further the effect of vitamin D deficiency on development of subclinical coronary artery disease (CAD), we conducted a longitudinal study demonstrating that vitamin D deficiency is
Correspondence: Shenghan Lai Johns Hopkins School of Medicine, 600 N Wolfe Street, Pathology \#30I, Baltimore, MD 21287, USA

$\mathrm{Tel}+\mathrm{I} 4106144837$

Fax + I 410502 2656

Email slai@jhmi.edu 
independently associated with development of subclinical CAD in human immunodeficiency virus (HIV)-infected African Americans. ${ }^{7}$

Mortality from CAD is higher in African Americans than in other racial groups, ${ }^{8}$ and premature CAD is a particular concern in HIV-infected African American chronic cocaine users. ${ }^{3,4}$ Although this may be attributable in part to a higher prevalence of traditional risk factors, including hypertension, diabetes, and the cluster of risk factors termed the metabolic syndrome, other factors are likely involved as well. One of the most important of these may be vitamin D deficiency, which is also increased in African Americans. ${ }^{9}$ We examined the incidence of subclinical coronary disease in HIV-infected African American chronic cocaine users with low Framingham risk scores and whether vitamin D deficiency was a risk factor in this important patient population.

Thus, the objectives of this study were to estimate the incidence of subclinical CAD with the use of cardiac computed tomography (CT) imaging in middle-aged asymptomatic African American chronic cocaine users with HIV infection and low Framingham-defined CAD risk, and to examine whether vitamin D deficiency is associated with development of subclinical CAD in this patient population.

\section{Materials and methods Study participants}

Between January 2006 and July 2010, 169 HIV-infected middle-aged African American cocaine users with low CAD risk and without known, or symptoms of, CAD were consecutively enrolled in a prospective study investigating the incidence of and risk factors for cardiac CT-defined subclinical CAD in Baltimore, MD.

Subclinical CAD was defined as the presence of coronary artery calcium (CAC) and/or coronary plaque by cardiac CT. Inclusion criteria were: age above 40 years; HIV positivity (determined by enzyme-linked immunosorbent assay and confirmed by Western blot test); chronic cocaine use, defined as chronic use of cocaine by any route for at least 6 months, administered at least four times a month; low CAD risk, defined as Framingham risk score $<10 \%$; ${ }^{10}$ and African American race (self-designated). The exclusion criteria included any evidence of clinical CAD. All the participants in this study are patients at the Johns Hopkins HIV clinic. We have access to their medical records, including history of electrocardiographic abnormalities and any cardiovascular diagnoses or symptoms, including chest pain and heart failure symptoms. Self-reported information was not used for defining CAD. Further exclusion criteria included any symptoms believed to be related to CAD, any evidence of renal insufficiency, known allergy to the contrast used for CT, and pregnancy. During the baseline visit, each subject was interviewed to obtain information on sociodemographic characteristics, cardiovascular risk (including cigarette smoking), alcohol use, illicit drug use behaviors, medical history, and all medications. Information about the frequency (how many times a day in the past week, in the past month), patterns/ forms of cocaine use (eg, speedball [intravenous use of a combination of heroin and cocaine] or crack), administration mode (eg, injection, smoking), and duration of cocaine use was collected. Information about use of other drugs, such as opiates, benzodiazepines, and methamphetamine was also collected.

A medical chart review was used to confirm information on medical history and medications that was provided by the subjects. Each subject also had a physical examination, and several tests were performed: namely, a fasting lipid profile, vitamin $\mathrm{D}$, high-sensitivity C-reactive protein test, 64-slice multidetector CT for CAC, and CT coronary angiography (contrast-enhanced). The study participants underwent reexaminations and interviews approximately 2 years later.

Of the 169 participants at baseline, 50 were diagnosed on coronary CT examination as having subclinical CAD and 119 were free of subclinical CAD. The 119 participants without subclinical CAD were included in this study.

The Committee on Human Research at the Johns Hopkins School of Medicine approved the study protocol, and all study participants provided their written informed consent. All procedures used in this study were in accordance with institutional guidelines.

\section{Blood pressure measurement}

Sitting systolic blood pressure (BP) and diastolic BP were measured twice with a standard mercury sphygmomanometer. A nurse at the clinic measured the study participant's arm circumference and applied a correctly sized cuff. The subject sat quietly for 5 minutes before the nurse obtained the systolic and diastolic BP. A second measurement was obtained 3 minutes later, and the average of the two readings was reported.

\section{Measurement of lipids}

Venous blood samples were obtained after an overnight fast from a large antecubital vein. Serum was separated by centrifugation $\left(2,000 \mathrm{~g}\right.$ for 15 minutes at $\left.4^{\circ} \mathrm{C}\right)$ and stored at $-75^{\circ} \mathrm{C}$ until assayed. Serum lipid variables, including total cholesterol, triglycerides, high-density lipoprotein cholesterol, and low-density lipoprotein cholesterol, were 
directly determined with an analyzer (Hitachi 747, Roche, Englewood, NJ, USA).

\section{Vitamin D measurement}

Sera were collected, centrifuged, and stored at $-75^{\circ} \mathrm{C}$ until analyzed. Serum $25(\mathrm{OH})$ vitamin D was determined by direct, competitive chemiluminescence immunoassay (DiaSorin, Stillwater, MN, USA). ${ }^{11}$ The level of minimum detection for $25(\mathrm{OH})$ vitamin $\mathrm{D}$ was $4 \mathrm{ng} / \mathrm{mL}$. This method accurately measures both D2 and D3 together, and is reported as total $25(\mathrm{OH})$ vitamin $\mathrm{D}$. The reference range is 32-100 ng/mL. This study identifies vitamin D deficiency according to the Framingham Offspring Study as serum $25(\mathrm{OH})$ vitamin $\mathrm{D}<10 \mathrm{ng} / \mathrm{mL}^{12}$

\section{Coronary angiography with a Siemens 64-slice multidetector CT scanner}

A noncontrast 64-slice multidetector CT scan was performed on a Sensation 64 Cardiac Siemens Medical Solutions scanner (Erlangen, Germany) to determine the CAC score with a sequential scan of $3 \mathrm{~mm}$ slices with prospective electrocardiographic triggering, $30 \times 0.6 \mathrm{~mm}$ detector collimation, and tube current $135 \mathrm{mAs}$ at $120 \mathrm{kV}$. Subsequently, coronary CT angiography was performed on the same equipment using $80 \mathrm{~mL}$ of iso-osmolar contrast agent (320 mg iodine $/ \mathrm{mL}$ ) injected at $4-5 \mathrm{~mL}$ per second. Imaging was performed with retrospective electrocardiographic gating, $32 \times 0.6 \mathrm{~mm}$ detector collimation with flying focal spot to give effective detector collimation of $64 \times 0.6 \mathrm{~mm}, 330 \mathrm{msec}$ gantry rotation, $850 \mathrm{mAs}$, and $120 \mathrm{kV}$. Subsequently, axial slices $0.75 \mathrm{~mm}$ thick were reconstructed at $0.4 \mathrm{~mm}$ intervals with a B25 kernel using a half-scan reconstruction algorithm with resulting temporal resolution of 165-185 msec. Ten reconstructions were done through the cardiac cycle at $10 \%$ increments in the R-R interval. If needed, metoprolol was administered prior to the scan to achieve a heart rate $<65$ beats per minute.

CAC score, volume, and mass were measured on a workstation (Leonardo, Syngo, Siemens Medical Solutions, Malvern, PA, USA). Regions of interest were placed over each of the coronary arteries with a threshold for pixels of greater than $130 \mathrm{HU}$ for determining calcified plaque. Coronary vessels were assessed for patency and stenoses using three-dimensional visualization tools after the axial images were reviewed for determination of anatomy, quality of the study, and appearance of the vessels. The Agatston method was used to signify development of incident $\mathrm{CAC}$.
One reviewer (EKF), blinded to the participants' risk factor profiles, independently evaluated the contrast-enhanced 64-slice multidetector CT scans by examining the axial slices, curved multiplanar reformations, and thin-slab maximum intensity projections. The coronary artery tree was segmented according to the modified American Heart Association classification, and the segments were investigated for plaque and luminal narrowing. The coronary arteries were divided into proximal, mid, and distal segments, with each segment investigated for luminal narrowing. Plaques were classified as calcified or noncalcified, and the degree of stenosis was classified as less than, equal to, or greater than $50 \%$ diameter stenosis. Diameter stenosis $\geq 50 \%$ was defined as significant coronary stenosis. This cutoff was used in prior studies as well. $^{13}$

\section{Statistical analysis}

Length of follow-up was calculated as the time elapsed from baseline to the second CT examination. Incidence rate was calculated by dividing the number of newly diagnosed cases by the person-years of follow-up. The $95 \%$ confidence interval (CI) for incidence was also calculated. Antiretroviral therapies were categorized on the basis of exposure to four classes, ie, nucleoside reverse transcriptase inhibitors (NRTIs), non-nucleoside reverse transcriptase inhibitors (NNRTIs), protease inhibitors, and other antiretroviral therapies.

Statistical analysis was performed using SAS software (version 9.3, SAS Institute, Inc., Cary, NC, USA). All continuous parameters were summarized by medians and interquartile ranges (IQRs), and all categorical parameters were summarized as proportions. To compare between-group differences, the nonparametric Wilcoxon two-sample test was used for continuous variables and the Fisher's exact test was used for categorical variables. The Framingham risk score was calculated to estimate the CAD risk. ${ }^{13}$

Survival analysis was used to identify risk factors for development of subclinical coronary atherosclerosis. The Kaplan-Meier method was used to estimate survivor functions, and the log-rank test was used to test the equality of survivor functions. Univariate Cox's proportional hazards regression models were first fitted to evaluate the crude association between development of coronary plaques and each individual factor, ie, age, sex, total cholesterol, high-density lipoprotein cholesterol, low-density lipoprotein cholesterol, triglycerides, vitamin D, high-sensitivity C-reactive protein, cigarette smoking, alcohol use, glucose level, history of diabetes, history of hypertension, systolic BP, diastolic BP, 
body mass index, baseline CD4 cell count, baseline HIV RNA quantification, duration of use of each antiretroviral drug, duration of antiretroviral use for each antiretroviral class (NRTIs, NNRTIs, protease inhibitors, fusion inhibitors, or integrase inhibitors), duration of any antiretroviral use, cocaine or other illicit drug use, and Framingham risk score.

Those factors that were significant at the $P \leq 0.20$ level in the univariate models were put into an initial multivariate Cox's proportional hazards regression model to identify factors that were independently associated with development of subclinical CAD. Those variables that ceased to make significant contributions to the models were eliminated in a stagewise manner, yielding a final model. The $P$-values reported are two-sided. A $P$-value $<0.05$ indicated statistical significance.

\section{Results}

\section{General characteristics}

Among the 169 subjects who underwent the first CT, 50 had evidence of subclinical CAD, yielding a prevalence rate of $29.6 \%$. The general and clinical characteristics of the study participants by development of subclinical CAD are presented in Table 1. Of the 119 participants in this study, 64 (53.8\%) were males. The median age was 45 (IQR 45-49) years. The median low-density lipoprotein cholesterol level was 75 (IQR 61-92) mg/dL. Ninety-one percent were cigarette smokers. The median Framingham risk score was 4.0 (IQR 3.0-7.0). The median vitamin D level was $18.0 \mathrm{ng} / \mathrm{dL}$ (IQR 11.0-26.0) $\mathrm{mg} / \mathrm{dL}$. The prevalence rate of vitamin D deficiency (serum 25 hydroxyvitamin $\mathrm{D}<10 \mathrm{ng} / \mathrm{mL}$ ) was $18.5 \%$. The median duration of cocaine use was 15 (IQR 9-20) years.

Table I Characteristics of study participants by development of subclinical CAD*

\begin{tabular}{|c|c|c|c|c|}
\hline \multirow[t]{2}{*}{ Characteristic } & \multirow{2}{*}{$\begin{array}{l}\text { Total } \\
(n=119)\end{array}$} & \multicolumn{2}{|l|}{ Subclinical CAD } & \multirow[t]{2}{*}{$P$-value } \\
\hline & & No $(n=108)$ & Yes $(n=I I)$ & \\
\hline Age (years) & $45(45-49)$ & $46(45-49)$ & $45(45-48)$ & 0.79 \\
\hline Male (\%) & 53.8 & 50.0 & 90.9 & 0.01 \\
\hline Family history of CAD (\%) & 26.1 & 27.8 & 9.1 & 0.18 \\
\hline Diabetes (\%) & 2.5 & 2.8 & 0.0 & 1.00 \\
\hline Hypertension (\%) & 13.5 & 18.2 & 13.0 & 0.64 \\
\hline Cigarette smoking (\%) & 90.8 & 90.7 & 90.9 & 0.99 \\
\hline Alcohol use (\%) & 91.6 & 90.7 & 100.0 & 0.29 \\
\hline Years of cocaine use & $15.0(9.0-20.0)$ & I $5.0(8.5-20.0)$ & $15.0(9.0-20.0)$ & 0.77 \\
\hline Years of HIV infection & $\mid 7.0(|0|-2 \mid .2)$. & $17.0(\mid 0.3-21.2)$ & $\mid 5.7(6.7-2 \mid .4)$ & 0.59 \\
\hline hsCRP $\geq 2$ mg/dL (\%) & 44.1 & 43.0 & 54.6 & 0.46 \\
\hline Vitamin D deficiency (\%) & 18.5 & 14.8 & 54.6 & 0.005 \\
\hline Serum $25(\mathrm{OH}) \mathrm{D}(\mathrm{ng} / \mathrm{mL})$ & $18(1 \mid-26)$ & $19(11-26)$ & $9(7-25)$ & 0.09 \\
\hline Systolic BP (mmHg) & $116(105-129)$ & $119(109-130)$ & $120(104-136)$ & 0.66 \\
\hline Diastolic BP (mmHg) & $72(62-79)$ & $72(62-79)$ & $69(64-80)$ & 0.86 \\
\hline Glucose (mg/dL) & 87 (79-96) & $86(79-94)$ & $89(76-101)$ & 0.65 \\
\hline BMI & $25.5(21.9-29.2)$ & $25.1(21.9-29.2)$ & $25.5(22.8-29.5)$ & 0.58 \\
\hline Baseline CD4 (cells/mm³) & $332(207-560)$ & $335(207-561)$ & 331 (202-409) & 0.62 \\
\hline Baseline viral load (copies/mL) & $5,515(300-60,000)$ & $3,445(202-57,110)$ & $39,149(13,148-82,285)$ & 0.09 \\
\hline eGFR $\left(\mathrm{mL} / \mathrm{min} / \mathrm{I} .73 \mathrm{~m}^{2}\right)$ & $103(85-118)$ & $103(84-119)$ & $101(91-104)$ & 0.68 \\
\hline Total cholesterol (mg/dL) & $158(\mid 37-182)$ & $156(135-182)$ & $161(151-183)$ & 0.53 \\
\hline LDL-C (mg/dL) & $75(61-92)$ & 74 (59-92) & $82(72-112)$ & 0.23 \\
\hline HDL-C (mg/dL) & $51(42-69)$ & $51(42-72)$ & $55(48-60)$ & 0.88 \\
\hline Triglycerides (mg/dL) & $110(85-158)$ & $112(87-160)$ & $108(72-138)$ & 0.38 \\
\hline NRTI use (month) & $48.0(17.0-96.0)$ & $49.5(24.0-92.5)$ & $24.0(1.9-111.1)$ & 0.49 \\
\hline NNRTI use (month) & $0(0.0-33.0)$ & $0.0(0.0-31.5)$ & $0.0(0.0-36.0)$ & 0.80 \\
\hline PI use (month) & $36.0(0.0-72.0)$ & $36.0(0.0-70.0)$ & $36.0(5.9-120.0)$ & 0.55 \\
\hline Any ART use (month) & $66.0(30.0-111.1)$ & $65.5(30.0-104.0)$ & $72.0(24.0-132.0)$ & 0.57 \\
\hline Framingham risk score (\%) & $4.0(3.0-7.0)$ & $4.0(3.0-7.0)$ & $7.0(3.0-8.0)$ & 0.11 \\
\hline
\end{tabular}

Note: *Median (interquartile range) for continuous variables, proportion (\%) for categorical variables.

Abbreviations: CAD, coronary artery disease; CD4, CD4 cell count; viral load, HIV RNA quantification; hsCRP, high-sensitivity C-reactive protein; BP, blood pressure; glucose, fasting glucose; BMI, body mass index $\left(\mathrm{kg} / \mathrm{m}^{2}\right)$; eGFR, estimated glomerular filtration rate ( $\left.\mathrm{mL} / \mathrm{min} / \mathrm{l} .73 \mathrm{~m}\right)^{2}$; LDL-C, low-density lipoprotein cholesterol; HDL-C, highdensity lipoprotein cholesterol; serum 25(OH) D, 25-hydroxyvitamin D; ART, antiretroviral therapy; NRTI, nucleoside reverse transcriptase inhibitor; NNRTI, nonnucleoside reverse transcriptase inhibitor; PI, protease inhibitor; HIV, human immunodeficiency virus; RNA, ribonucleic acid. 
Among the 119 participants included in this study, subclinical CAD was detected in 11 during the follow-up visit. Of the 11 patients with incident $\mathrm{CAD}$, six developed incident $\mathrm{CAC}$, two developed incident plaque (one plaque with significant stenosis), and three developed incident CAC and plaque.

Compared with those who remained free of subclinical CAD, those who developed subclinical CAD were more likely to be male $(P=0.01)$ and to have vitamin D deficiency $(P=0.005)$. None of the participants experienced a cardiovascular event during the follow-up period.

\section{Incidence of subclinical CAD}

The total sum of person-years of follow-up was 289.6. The mean follow-up time was $2.43 \pm 1.15$ years. Subclinical CAD was detected in 11 of the 119 participants on the second cardiac CT, yielding an overall incidence of 3.80 per 100 person-years (95\% CI 1.90-6.80).

For 22 participants who were vitamin D-deficient, the total sum of person-years of follow-up was 53.2 and the mean follow-up time was $2.42 \pm 1.18$ years. Subclinical CAD was detected in six of these 22 on the second cardiac CT, yielding an overall incidence of 11.3 per 100 person-years (95\% CI 4.14-24.6).

For 97 participants who were not deficient in vitamin D, the total sum of person-years of follow-up was 236.4 and the mean follow-up time was $2.44 \pm 1.15$ years. Subclinical CAD was detected in five of these 97 on the second cardiac $\mathrm{CT}$, yielding an overall incidence of 2.1 per 100 person-years (95\% CI 0.69-4.94).

\section{Association between vitamin D deficiency and time to development of subclinical CAD}

Kaplan-Meier curves of time to development of subclinical CAD by vitamin D deficiency status are presented in Figure 1 . According to the log-rank test, time to development of subclinical CAD in those who were vitamin D-deficient was significantly shorter than that in those who were not vitamin D-deficient (log-rank test, $P=0.002$ ).

\section{Factors associated with development of subclinical CAD}

By univariate Cox's proportional hazards regression analyses, among all the factors examined, including age, sex, cigarette smoking, alcohol use, history of diabetes, history of hypertension, duration of HIV infection, C-reactive protein, serum

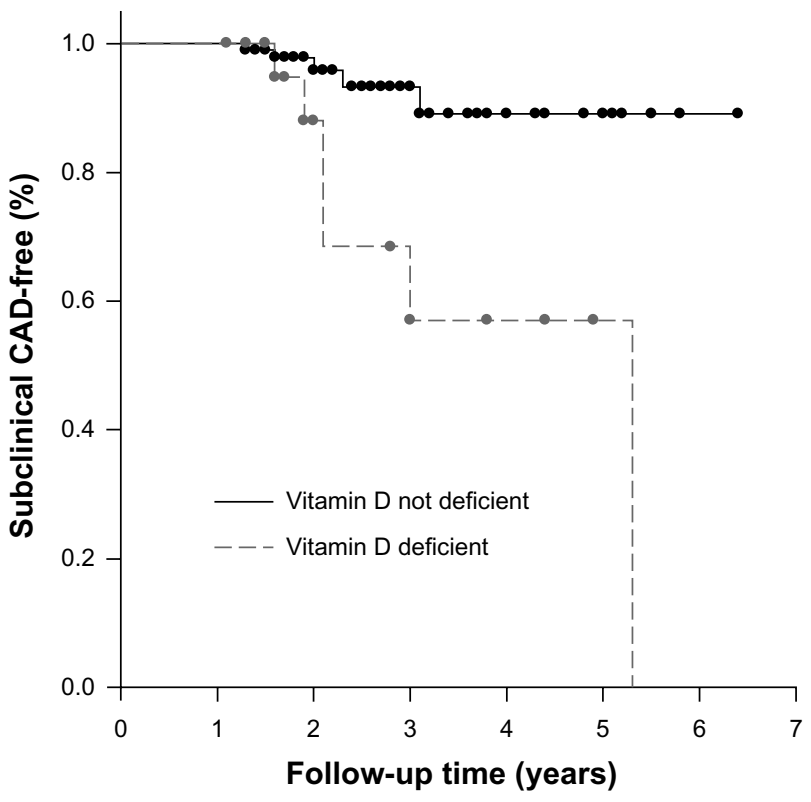

Figure I Kaplan-Meier subclinical CAD-free survival curve by vitamin D deficiency status. Survival curves by vitamin $D$ deficiency status were statistically different (logrank test, $P=0.002$ ).

Abbreviation: CAD, coronary artery disease.

$25(\mathrm{OH})$ vitamin D level, vitamin D deficiency, systolic blood pressure, diastolic blood pressure, body mass index, glucose, baseline CD4 count, baseline HIV viral load, total cholesterol, low-density lipoprotein cholesterol, high-density lipoprotein cholesterol, triglycerides, duration of antiretroviral medication use (NRTIs, NNRTIs, protease inhibitors, and other antiretroviral therapies), and Framingham risk score, only female sex, serum 25(OH) vitamin D level, vitamin D deficiency, and Framingham risk score were associated with development of subclinical CAD at the $\leq 0.20$ level.

The final Cox's regression model indicated that only vitamin D deficiency (adjusted hazard ratio 5.32, 95\% CI 1.62-17.5) was independently associated with development of subclinical CAD over the course of the study (Table 2).

\section{Discussion}

The present study investigated the incidence of, and the risk factors for, subclinical CAD in HIV-infected African American cocaine users with low CAD risk. The main strength of this investigation is that the absence or presence of subclinical CAD was defined using coronary CT scans and thus the study participants were proven on cardiac $\mathrm{CT}$ to be free of subclinical CAD. The first objective of this study was to estimate the incidence rate of subclinical CAD in HIV-infected African American cocaine users with low Framingham-defined CAD risk. According to the American Heart Association the lipid 
Table 2 Demographic, laboratory, and clinical factors in relation to risk of development of subclinical CAD. Proportional hazards regression analysis*

\begin{tabular}{|c|c|c|}
\hline \multirow[t]{2}{*}{ Variable } & \multicolumn{2}{|l|}{ Subclinical CAD } \\
\hline & $\begin{array}{l}\text { Crude HR } \\
(95 \% \mathrm{Cl})\end{array}$ & $\begin{array}{l}\text { Adjusted HR } \\
(95 \% \mathrm{Cl})\end{array}$ \\
\hline Age (years) & $0.98(0.83-1.14)$ & \\
\hline \multicolumn{3}{|l|}{ Sex } \\
\hline Male & 1.00 & \\
\hline Female & $0.13(0.02-1.02)$ & \\
\hline \multicolumn{3}{|l|}{ Cigarette smoking } \\
\hline Never & 1.00 & \\
\hline Ever & $0.99(0.13-7.84)$ & \\
\hline \multicolumn{3}{|l|}{ Alcohol use } \\
\hline No & 1.00 & \\
\hline Yes & not estimable & \\
\hline \multicolumn{3}{|l|}{ Diabetes } \\
\hline No & 1.00 & \\
\hline Yes & not estimable & \\
\hline \multicolumn{3}{|l|}{ Hypertension } \\
\hline No & 1.00 & \\
\hline Yes & $2.13(0.45-10.1)$ & \\
\hline Years of HIV infection & $0.96(0.88-1.05)$ & \\
\hline $\mathrm{hsCRP} \geq 2 \mathrm{mg} / \mathrm{dL}$ & $1.13(0.34-3.77)$ & \\
\hline Serum $25(\mathrm{OH}) \mathrm{D}(\mathrm{ng} / \mathrm{mL})$ & $0.95(0.89-1.02)$ & \\
\hline \multicolumn{3}{|l|}{ deficiency } \\
\hline Systolic BP (mmHg) & I.0I (0.97-I.04) & \\
\hline Diastolic BP (mmHg) & $1.01(0.95-1.06)$ & \\
\hline Glucose $(\mathrm{mg} / \mathrm{dL})$ & $1.01(0.98-1.03)$ & \\
\hline BMI $\left(\mathrm{kg} / \mathrm{m}^{2}\right)$ & $0.98(0.88-1.10)$ & \\
\hline Baseline CD4 & $1.00(0.99-1.00)$ & \\
\hline \multicolumn{3}{|l|}{ count (cells $/ \mathrm{mm}^{3}$ ) } \\
\hline $\begin{array}{l}\text { Baseline viral load } \\
\text { (copies } / \mathrm{mL} \text { ) }\end{array}$ & $1.18(0.91-1.53)$ & \\
\hline Total cholesterol (mg/dL) & $1.00(0.99-1.02)$ & \\
\hline LDL-C (mg/dL) & I.0I (0.99-I.03) & \\
\hline HDL-C (mg/dL) & $0.99(0.96-1.02)$ & \\
\hline Triglycerides (mg/dL) & $1.00(0.98-1.01)$ & \\
\hline \multicolumn{3}{|l|}{ NRTI use (months) } \\
\hline \multirow[t]{2}{*}{ Zidovudine } & 0.00 & \\
\hline & (0.00-not estimable) & \\
\hline Combivir ${ }^{\circledR}$ & $0.95(0.80-1.12)$ & \\
\hline \multirow[t]{2}{*}{ Epivir $^{\circledast}$} & 0.08 & \\
\hline & (0.00-not estimable) & \\
\hline Epzicom ${ }^{\circledast}$ & $1.00(0.98-1.02)$ & \\
\hline \multirow[t]{2}{*}{ Trizivir $^{\circledR}$} & 0.69 & \\
\hline & (0.00-not estimable) & \\
\hline Zerit $^{\circledR}$ & $1.00(0.98-1.03)$ & \\
\hline Truvada ${ }^{\circledR}$ & $1.00(0.99-1.02)$ & \\
\hline \multirow[t]{2}{*}{ Viread $^{\circledR}$} & 0.61 & \\
\hline & (0.00-not estimable) & \\
\hline \multirow[t]{2}{*}{ Ziagen $^{\circledR}$} & 0.39 & \\
\hline & (0.00-not estimable) & \\
\hline \multicolumn{3}{|l|}{ NNRTI use (month) } \\
\hline Sustiva ${ }^{\circledR}$ & $1.00(0.98-1.02)$ & \\
\hline \multirow[t]{2}{*}{ Etravirine } & 0.58 & \\
\hline & (0.00-not estimable) & \\
\hline
\end{tabular}

(Continued)
Table 2 (Continued)

\begin{tabular}{|c|c|c|}
\hline \multirow[t]{2}{*}{ Variable } & \multicolumn{2}{|l|}{ Subclinical CAD } \\
\hline & $\begin{array}{l}\text { Crude HR } \\
(95 \% \mathrm{CI})\end{array}$ & $\begin{array}{l}\text { Adjusted HR } \\
(95 \% \mathrm{Cl})\end{array}$ \\
\hline \multirow[t]{2}{*}{ Nevirapine } & 0.15 & \\
\hline & (0.00-not estimable) & \\
\hline \multicolumn{3}{|l|}{ PI use (month) } \\
\hline \multirow[t]{2}{*}{ Crixivan $^{\circledR}$} & 0.03 & \\
\hline & (0.00-not estimable) & \\
\hline Kaletra $^{\circledR}$ & $1.00(0.98-1.03)$ & \\
\hline Lexiva $^{\circledR}$ & $1.01(0.97-1.03)$ & \\
\hline Norvir $^{\circledR}$ & $1.00(0.99-1.01)$ & \\
\hline Prezista ${ }^{\circledR}$ & $0.99(0.93-1.06)$ & \\
\hline Reyataz $^{\circledR}$ & $1.00(0.99-1.01)$ & \\
\hline \multirow[t]{2}{*}{ Viracept ${ }^{\circledR}$} & 0.14 & \\
\hline & (0.00-not estimable) & \\
\hline \multicolumn{3}{|l|}{ Other ART use (month) } \\
\hline Isentress ${ }^{\circledR}$ & $0.90(0.71-1.13)$ & \\
\hline \multirow[t]{2}{*}{ Seizentry ${ }^{\circledR}$} & 0.71 & \\
\hline & (0.00-not estimable) & \\
\hline Any ART use (month) & $1.00(0.99-1.01)$ & \\
\hline Framingham risk score (\%) & $1.20(0.97-1.48)$ & \\
\hline
\end{tabular}

Notes: *Crude hazards ratios (HRs) were obtained from univariate Cox's proportional hazards model. The adjusted HRs were obtained from the final Cox's proportional hazard model. Those factors that were significant at the $P \leq 0.20$ level in the univariate Cox's models were put into an initial multivariate Cox's proportional hazards regression model to identify factors that were independently associated with development of subclinical CAD. Those variables that ceased to make significant contributions to the models were eliminated in a stagewise manner, yielding a final model. Kaletra ${ }^{\circledR}$, Abbott Laboratories, Abbott Park, IL, USA; Lexiva ${ }^{\circledR}$, Glaxo Smith Kline, Brentford, London, UK; Norvir ${ }^{\circledast}$, AbbVie Inc., North Chicago, IL, USA; Prezista ${ }^{\circledR}$, Janssen Pharmaceuticals, Inc., Titusville, NJ, USA; Reyataz ${ }^{\circledR}$, BristolMyers Squibb, New York, NY, USA; Viracept ${ }^{\oplus}$, Agouron Pharmaceuticals Inc., La Jolla, CA, USA.

Abbreviations: $C A D$, coronary artery disease; $C D 4, C D 4$ cell count; viral load, HIV RNA quantification; hsCRP, high-sensitivity C-reactive protein; BP, blood pressure; glucose, fasting glucose; BMI, body mass index $\left(\mathrm{kg} / \mathrm{m}^{2}\right)$; LDL-C, low density lipoprotein cholesterol; HDL-C, high density lipoprotein cholesterol; serum $25(\mathrm{OH}) \mathrm{D}$, 25-dihydroxyvitamin D; vitamin D deficiency, serum $25(\mathrm{OH}) \mathrm{D}<10 \mathrm{ng} / \mathrm{mL}$; NRTI, nucleoside reverse transcriptase inhibitor; NNRTI, nonnucleoside reverse transcriptase inhibitor; Pl, protease inhibitor; Cl, confidence interval; HIV, human immunodeficiency virus; RNA, ribonucleic acid.

profiles for this population were unexpectedly healthy. ${ }^{18}$ For example, the median cholesterol level in this population was 158 (IQR 137-182) mg/dL, while the level considered desirable by the American Heart Association is $<200 \mathrm{mg} / \mathrm{dL}$; the median low-density lipoprotein level in this population was 75 (IQR 61-92) mg/dL, while the optimal level as determined by the American Heart Association is $<100 \mathrm{mg} / \mathrm{dL}$.

Although the incidence of subclinical CAD has been reported in HIV-infected African Americans, ${ }^{7}$ the incidence of subclinical CAD in those with low CAD risk has not. Our findings demonstrate that the overall incidence of subclinical CAD in this population is 3.80 per 100 person-years $(95 \%$ CI 1.90-6.80), which is slightly lower than that in HIVinfected African Americans. ${ }^{7}$ While the incidence in those who were not vitamin D-deficient was only 2.1 per 100 
person-years (95\% CI $0.69-4.94)$, the incidence in those who were vitamin D-deficient was 11.3 per 100 person-years (95\% CI 4.14-24.6), which is provocatively high, despite the fact that the participants in this study were all at low risk according to the Framingham risk score. Since acute myocardial infarction or sudden cardiac death is often the first clinical manifestation of CAD in up to $50 \%$ of patients in the US, early detection of subclinical CAD, especially in those with low CAD risk as defined by Framingham score, before clinical CAD events occur, and early identification of risk factors for development of subclinical CAD may be critical in this population. ${ }^{8,14-16}$ The second objective of this study was to identify risk factors for development of subclinical CAD in HIV-infected African American cocaine users with low CAD risk.

The present study suggests that vitamin D deficiency is the only factor that is independently associated with development of subclinical CAD in this population over a mean follow-up of 2.4 years. The association between vitamin $\mathrm{D}$ deficiency and clinical CAD in general populations has been extensively investigated. A study analyzing a large electronic medical records database to determine the prevalence of vitamin D deficiency and the relationship of vitamin D levels to prevalent and incident cardiovascular risk factors and diseases in a general health care population ${ }^{17}$ revealed that vitamin D levels were highly associated with CAD, myocardial infarction, heart failure, and stroke, as well as with incident death, heart failure, $\mathrm{CAD} /$ myocardial infarction, and stroke. ${ }^{17}$ The Framingham Offspring Study, which evaluated 1,739 study participants without prior CAD, reported that vitamin $\mathrm{D}$ deficiency (defined as $25(\mathrm{OH})$ vitamin $\mathrm{D}<10 \mathrm{ng} / \mathrm{mL}$ ) was associated with an increased risk for developing a first cardiovascular event after 5 years of follow-up as compared with subjects with $25(\mathrm{OH})$ vitamin D levels $>15 \mathrm{ng} / \mathrm{mL}$ (hazard ratio $1.80,95 \% \mathrm{CI} 1.05-3.08) .{ }^{12}$ This study also suggested that the association between vitamin $\mathrm{D}$ concentration and cardiovascular risk was nonlinear, with increased hazard for cardiovascular events at a vitamin D concentration below $15-20 \mathrm{ng} / \mathrm{mL}$. A recent study in cocaine users suggests that vitamin D deficiency (adjusted odds ratio 2.18, 95\% CI $1.07-4.43$ ) is independently associated with the presence of significant coronary stenosis after controlling for traditional risk factors in cocaine users. ${ }^{5}$ Nevertheless, controversies remain regarding the association between vitamin $\mathrm{D}$ and CAD. A systematic review on vitamin $\mathrm{D}$ and cardiometabolic outcomes revealed that five of the nine analyses found that lower vitamin $\mathrm{D}$ concentration was associated with increased risk for incident CAD. ${ }^{19}$ Among the studies that evaluated fatal CAD, two of three reported that higher vitamin D levels were associated with significantly lower fatal CAD events, and one study found no significant association with fatal CAD events. ${ }^{19}$

According to the present study, vitamin D deficiency is associated with a five-fold increased risk of developing subclinical CAD. This finding suggests new cost-effective approaches to prevention of CAD and opportunities to investigate the mechanisms responsible for development of subclinical CAD.

The mechanisms explaining the association between vitamin $\mathrm{D}$ deficiency and development of subclinical CAD remain unclear. It has been reported that low circulating $25(\mathrm{OH})$ vitamin D levels are associated with several risk factors for $\mathrm{CAD}$, such as obesity, diabetes, hypertension, dyslipidemia, and inflammatory markers, such as C-reactive protein and interleukin- $6 .{ }^{20-24} \mathrm{~A}$ large cohort study of 3,258 patients scheduled for coronary angiography with a median follow-up of 7.7 years found that low 25-hydroxyvitamin D and 1,25-dihydroxyvitamin D levels are independently associated with all-cause and cardiovascular mortality. ${ }^{25}$ Nevertheless, an association between these risk factors by low vitamin D levels may not be sufficient to explain why vitamin D deficiency is associated with the rapid development of subclinical CAD observed in this study.

The findings of this study do not support a dose-response relationship between subclinical CAD and vitamin D levels. Instead, the data derived from this investigation appear to suggest that there is a threshold level of vitamin $\mathrm{D}(10 \mathrm{ng} / \mathrm{mL})$ above which the effect of vitamin $\mathrm{D}$ on subclinical CAD is diminished (Figure 2).

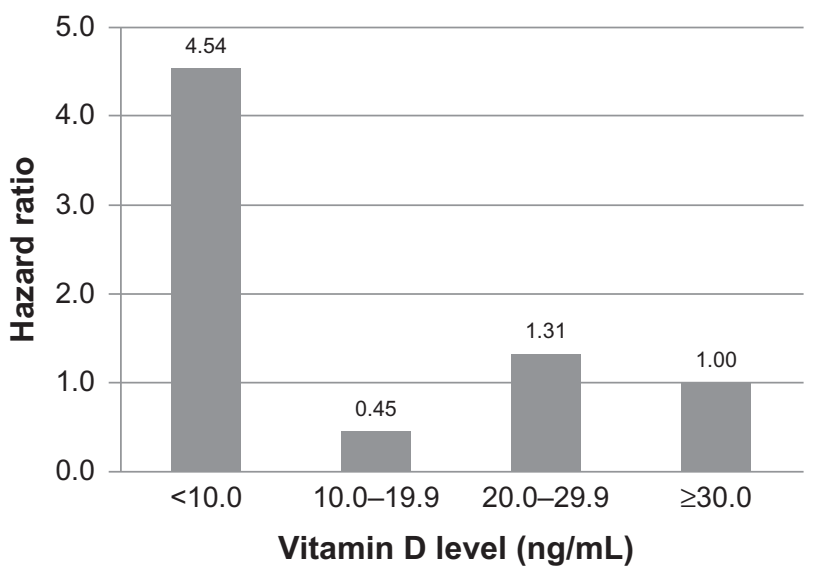

Figure 2 Hazard ratios of subclinical coronary artery disease at different vitamin $D$ levels. The data suggests that there is a threshold level of vitamin $D(I 0 \mathrm{ng} / \mathrm{mL})$ above which the effect of vitamin $D$ on subclinical coronary artery disease is diminished. 
Although the literature has suggested that antiretroviral therapy may be associated with an increased risk of subclinical $\mathrm{CAD},{ }^{7}$ this study found no evidence suggesting that CD4 count, HIV viral load, or antiretroviral therapy use were significantly associated with subclinical CAD. A study with a larger sample size is needed to examine the effects of CD4 count, HIV vital load, and cocaine use on the development of subclinical CAD.

There are several limitations that need to be acknowledged and addressed regarding the present study. First, the participants were not a random sample of African Americans with HIV infection, and therefore the results may not be generalizable to other populations. Second, since a large majority of participants were cigarette smokers, the effects of cigarette smoking on subclinical CAD or the joint effects of vitamin D deficiency and cigarette smoking on subclinical CAD could not be fully evaluated, either individually or combined. Third, the sample size was small and the follow-up time was short. Thus, the CIs of the hazard ratios are quite wide, indicating great uncertainty in the point estimate of hazard ratios. Due to the small sample size and the low number of endpoints, the generalizability of the findings is quite limited. The study was underpowered to fully evaluate risk factors that may be associated with development of incident CAD. Fourth, since this study was performed in African American cocaine users living in inner city Baltimore, the effects of some socioeconomic variables on subclinical CAD could not be completely controlled for. Fifth, as eight of nine participants developed $\mathrm{CAC}<10$, our study may suffer from interscan variation in CAC. It has been reported that the largest score variation in CAC occurred in the left main coronary artery. ${ }^{26}$ In our study, no CAC was identified in the left main coronary artery. Sixth, since the baseline data in this prospective study were not collected at the time of diagnosis of HIV infection, the effect of HIV infection and antiretroviral therapy use on vitamin D levels could not be evaluated. Lastly, a retrospective study reported that vitamin D levels may be influenced by duration of antiretroviral therapy use. ${ }^{27} \mathrm{~A}$ larger prospective study could examine this alleged association.

Despite its limitations, this study demonstrates a very high incidence of subclinical CAD in HIV-infected African American cocaine users with vitamin D deficiency and low Framingham-defined CAD risk. This high incidence of subclinical CAD may confirm the incremental predictive value for subclinical CAD by screening vitamin D deficiency in addition to risk assessment by conventional Framingham risk in HIV-infected African American cocaine users. Well designed, randomized trials are warranted to determine the safety and efficacy of vitamin D supplementation in HIV-infected African American cocaine users with vitamin D deficiency.

\section{Acknowledgments}

This study was supported by grants from the National Institute on Drug Abuse, National Institutes of Health (NIH R01-DA 12777, DA15020, and DA25524). We thank the study participants for their contributions to this research.

\section{Disclosure}

The authors report no conflicts of interest in this work.

\section{References}

1. Lai S, Lai H, Meng Q, et al. Effect of cocaine use on coronary calcification among black adults in Baltimore. Am J Cardiol. 2002;90:326-328.

2. Lai S, Lima JA, Lai H, et al. HIV-1 infection, cocaine, and coronary calcification. Arch Intern Med. 2005;165:690-695.

3. Lai S, Fishman EK, Lai H, et al. Long-term cocaine use and antiretroviral therapy are associated with silent coronary artery disease in cardiovascularly asymptomatic African Americans with HIV infection. Clin Infect Dis. 2008;46:600-610.

4. Lai S, Bartlett J, Lai H, et al. Long-term combination antiretroviral therapy is associated with the risk of coronary plaques in African Americans with HIV infection. AIDS Patient Care STDS. 2009;23:815-824.

5. Lai H, Fishman EK, Gerstenblith G, et al. Vitamin D deficiency is associated with significant coronary stenoses in asymptomatic African American chronic cocaine users. Int J Cardiol. 2012;158:211-216.

6. Lai H, Gerstenblith G, Fishman EK, et al. Vitamin D deficiency is associated with silent coronary artery disease in cardiovascularly asymptomatic African Americans with HIV infection. Clin Infect Dis. 2012;54:1747-1755.

7. Lai H, Detrick B, Fishman EK, et al. Vitamin D deficiency is associated with the development of subclinical coronary artery disease in African Americans with HIV infection: a preliminary study. J Investig Med. 2012;60:801-807.

8. Nesby-O'Dell S, Scanlon KS, Cogswell ME, et al. Hypovitaminosis D prevalence and determinants among African American and white women of reproductive age: third National Health and Nutrition Examination Survey, 1988-1994. Am J Clin Nutr. 2002;76: 187-192.

9. Ferdinand KC. Coronary heart disease and lipid-modifying treatment in African American patients. Am Heart J. 2004;147:774-782.

10. Wilson PW, D'Agostino RB, Levy D, et al. Prediction of coronary heart disease using risk factor categories. Circulation. 1998;97:1837-1847.

11. Ersfeld DL, Rao DS, Body JJ, et al. Analytical and clinical validation of the $25(\mathrm{OH})$ vitamin D assay for the Liaison automated analyzer. Clin Biochem. 2004;37:867-874.

12. Wang TJ, Pencina MJ, Booth SL, et al. Vitamin D deficiency and risk of cardiovascular disease. Circulation. 2008;117:503-511.

13. Miller JM, Rochitte CE, Dewey M, et al. Diagnostic performance of coronary angiography by 64-row CT. N Engl J Med. 2008; 359:2324-2336.

14. Roger VL, Go AS, Lloyd-Jones DM, et al. American Heart Association Statistics Committee and Stroke Statistics Subcommittee. Heart disease and stroke statistics - 2011 update: a report from the American Heart Association. Circulation. 2011;123:e18-e209.

15. Falk E, Shah PK, Fuster V. Coronary plaque disruption. Circulation. 1995;92:657-671.

16. Anand DV, Lim E, Raval U, et al. Prevalence of silent myocardial ischemia in asymptomatic individuals with subclinical atherosclerosis detected by electron beam tomography. $J$ Nucl Cardiol. 2004;11: 450-457. 
17. Anderson JL, May HT, Horne BD, et al. Relation of vitamin D deficiency to cardiovascular risk factors, disease status, and incident events in a general healthcare population. Am J Cardiol. 2010;106:963-968.

18. American Heart Association. [homepage on the Internet]. What your cholesterol levels mean. [updated Sep 6, 2013] Available from: http://www heart.org/HEARTORG/Conditions/Cholesterol/AboutCholesterol/ What-Your-Cholesterol-Levels-Mean_UCM_305562_Article.jsp. Accessed September 8, 2013.

19. Pittas AG, Chung M, Trikalinos T, et al. Systematic review: vitamin D and cardiometabolic outcomes. Ann Intern Med. 2010;152:307-314.

20. Joergensen C, Reinhard H, Schmedes A, et al. Vitamin D levels and asymptomatic coronary artery disease in type 2 diabetic patients with elevated urinary albumin excretion rate. Diabetes Care. 2012;35:168-172.

21. Wortsman J, Matsuoka LY, Chen TC, et al. Decreased bioavailability of vitamin D in obesity. Am J Clin Nutr. 2000;72:690-693.

22. Martins D, Wolf M, Pan D, et al. Prevalence of cardiovascular risk factors and the serum levels of 25-hydroxyvitamin D in the United States: data from the Third National Health and Nutrition Examination Survey. Arch Intern Med. 2007;167:1159-1165.
23. Krause R, Bühring M, Hopfenmüller W, et al. Ultraviolet B and blood pressure. Lancet. 1998;352:709-710.

24. Zittermann A. Vitamin D and disease prevention with special reference to cardiovascular disease. Prog Biophys Mol Biol. 2006;92:39-48.

25. Dobnig H, Pilz S, Scharnagl H, et al. Independent association of low serum 25-hydroxyvitamin D and 1,25-dihydroxyvitamin D levels with all-cause and cardiovascular mortality. Arch Intern Med. 2008;168: 1340-1349.

26. Yoon HC, Goldin JG, Greaser LE 3rd, et al. Interscan variation in coronary artery calcium quantification in a large asymptomatic patient population. AJR Am J Roentgenol. 2000;174:803-809.

27. Theodorou M, Sersté T, Van Gossum M, et al. Factors associated with vitamin D deficiency in a population of 2044 HIV-infected patients Clin Nutr. April 25, 2013. [Epub ahead of print.]
Vascular Health and Risk Management

\section{Publish your work in this journal}

Vascular Health and Risk Management is an international, peerreviewed journal of therapeutics and risk management, focusing on concise rapid reporting of clinical studies on the processes involved in the maintenance of vascular health; the monitoring, prevention and treatment of vascular disease and its sequelae; and the involvement of

\section{Dovepress}

metabolic disorders, particularly diabetes. This journal is indexed on PubMed Central and MedLine. The manuscript management system is completely online and includes a very quick and fair peer-review system, which is all easy to use. Visit http://www.dovepress.com/ testimonials.php to read real quotes from published authors. 